\title{
Influence of Horizontal Pipe Length to Flooding of Countercurrent of Water-Air Flow in Complex Pipe
}

\author{
Samuel Hartonoa, Deendarlianto ${ }^{b}$, Indarto ${ }^{c}$, Apip Badarudin ${ }^{d}$ \\ ${ }^{a}$ Magister Program of Mechanical Engineering, Gadjah Mada University \\ b,c Department of Mechanical and Industrial Engineering, Gadjah Mada University \\ d Doctoral Program of Mechanical Engineering, Gadjah Mada University \\ Jl. Grafika No. 2, Yogyakarta 55281, Indonesia \\ e-mail: samuel.hartono@mail.ugm.ac.id ${ }^{\star 1}$, deendarlianto@ugm.ac.id ${ }^{2}$
}

\begin{abstract}
This research has been conducted study the effect of horizontal pipe length on flooding phenomenon. Observation of the flow phenomenon has used high speed camera. Working fluids for this study were water-air and the water flow was countercurrent to the air through a hot leg simulator. Hot leg simulator consisted of an acrylic horizontal pipe with inside diameter of $25.4 \mathrm{~mm}$ and an elbow with inclination angle of $50^{\circ}$. The ratio of length to diameter pipe used in this study $L / D=25, L / D=50$ and $L / D=94.5$. Water superficial velocity (JL) were $0.016 \mathrm{~m} / \mathrm{s}, 0.049 \mathrm{~m} / \mathrm{s}, 0.082 \mathrm{~m} / \mathrm{s}$. For each water superficial velocity, air superficial velocity (JG) was increased gradually with $0.1646 \mathrm{~m} / \mathrm{s}$ from $0 \mathrm{~m} / \mathrm{s}$ until flooding phenomenon appeared. Time interval to change air superficial velocity was 15 seconds. The result of this study was flooding phenomenon appeared earlier for higher $L / D$, and it was observed that the onset of flooding shifted toward the bend. It was also observed that flooding phenomenon shifted away from the bend for higher JL while L/D kept constant.
\end{abstract}

Keywords: hot leg; L/D; flooding; countercurrent flow; superficial velocity

\section{INTRODUCTION}

In the system of counter current of water-air flow in horizontal pipe, the air phase is above water fase because of air density is lower than density of water. This flow system generally is known as stratified as noted by Dukler and Taitel [1]. The pattern of stratified counter current flow will be developed in the boundary of water and air phase. The flow pattern will be stable in the range of certain superficial velocity of water (JL) and air (JG). For higher JG of this range, intermittent flow will occurs on the boundary of water-air phase.

When JG is set higher, then wave on inter phase boundary will grow higher in amplitude and start to generate slug. When JG is set even higher (for fixed superficial velocity of water), then generated slug will be carried by air flow and generate one directional flow of water-air phase. This phenomenon is known as flooding or Countercurrent Flow Limitation (CCFL).

The generation of CCFL in hot leg line of nuclear reactor need to be avoided since it will disturbing cooling system in nuclear reactor terrace. CCFL will make cooling water from steam generator can not flowing into reactor terrace because experience one directional flow which flow back into steam generator. When it is occured, the amount of cooling water in reactor terrace will gradually decrease and may lead to accident in the nuclear reactor. The phenomenon of failure in cooling of reactor is known as LOCA (Loss of Coolant Accident).

Previous researches in flooding phenomenon found in literature were: Kang et.al. [2], which investigated the flooding phenomenon in horizontal pipe of $40 \mathrm{~mm}$ and $80 \mathrm{~mm}$ of 
diameter which connected to inclined elbow. In this investigation, it was found that floding phenomenon (CCFL) was preluded by occurence of hydraulic jump in flow. Bigger velocity of water mass flowing into elbow, the position of hydraulic jump was further from it. Along with the increase of superficial velocity of air, in the peak of hydraulic jump there were small bubbles. The small bubbles will grow into slug which inflows in same direction with direction of air flow. The research also investigated the influence of pipe length to flooding. It employed pipe of $928 \mathrm{~mm}, 2000 \mathrm{~mm}$ and $3338 \mathrm{~mm}$ of length and the result shown that the longer of the pipe, the lower superficial velocity of air (JG) at time of flooding occurence as shown in Figure 1.1.

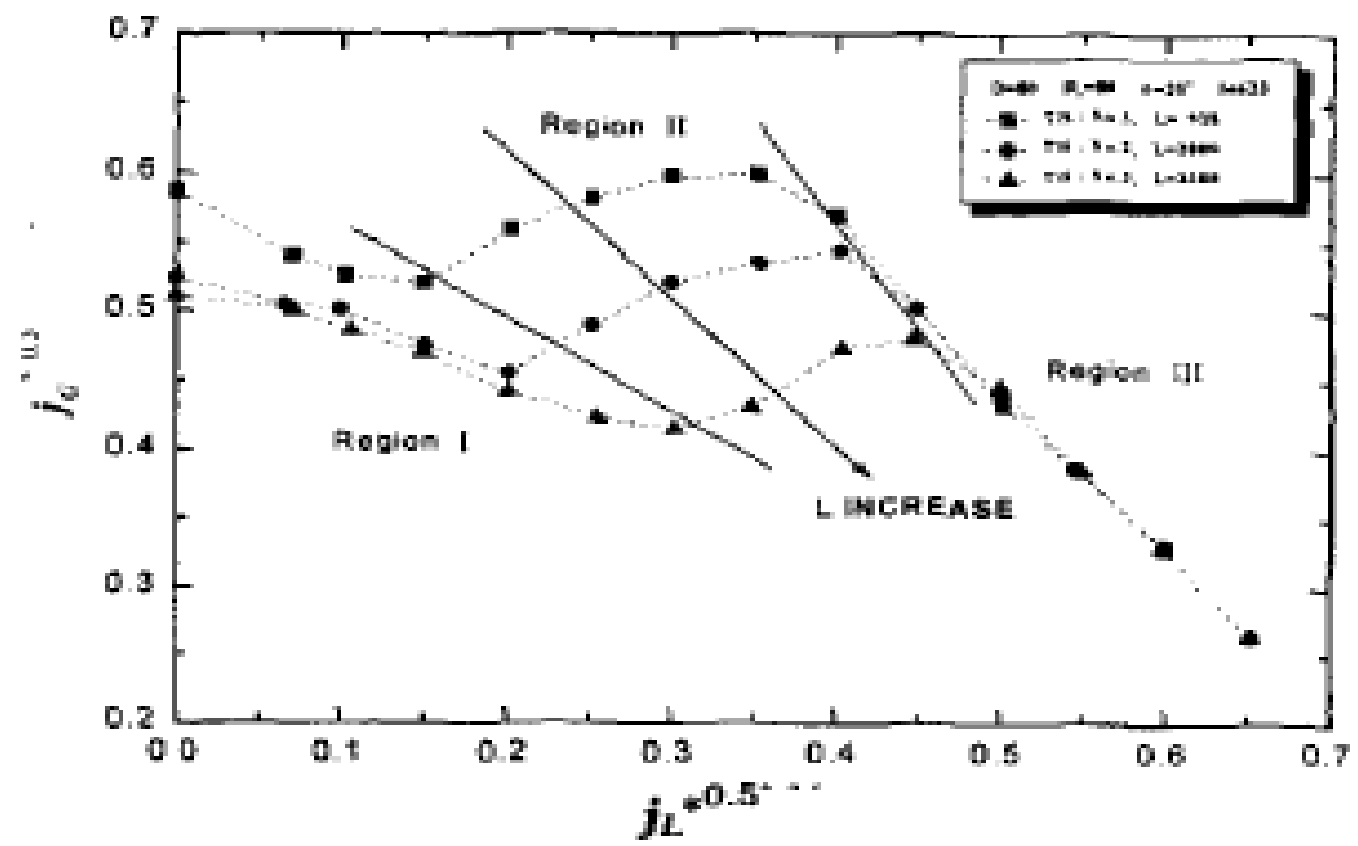

Figure 1.1 Curve of influence of pipe length to flooding. For $L=928 \mathrm{~mm}, 2000 \mathrm{~mm}, 3388 \mathrm{~mm}$. Kang et.al. [2]

Deendarlianto et.al. [3] conducted research on floding phenomenon in horizontal pipe of rectangular shape with surface area of $0.25 \times 0.05 \mathrm{~m}$ of $2.59 \mathrm{~m}$ of length. The pipe was connected to elbow with inclination of $50^{\circ}$. The research showed slug generation which precedes flooding in water-air phase flow. Deendarlianto et.al. gave definition of CCFL as boundary point of maximum velocity of air flow so that velocity of water flow inside testing section equal to velocity of water flow out from testing section. Another finding was onset of flooding is influenced by pressure drop between inlet section of water and air. Bigger pressure drop, bigger velocity of air mas flow required to generate flooding.

Apip et.al. [4] conducted study on the pattern of contra current water-air flow and stated that intermittent flow on the boundary of water-air phase started from the occurence of small bubbles which grow into slug. Slug generation was occured easily when superficial velocity of water was set higher. One of the ways to detect the ocurence of slug phenomenon was by indication of pressure drop between upper plenum and lower plenum. The result was in agreement with Deendarlianto et.al. [3].

Siddiqui et.al [5] conducted study on the influence of length of almost horizontal pipe which has inclination angle of $90^{\circ}$ to flooding phenomenon. Almost horizontal pipe used for investigation had range of inclination angle of approximately $0.03^{\circ}$. Ratio of length to diameter of pipe (L/D) was 24 and 62 . The result obtained from the research was for fixed diameter, bigger L/D (longer the pipe) made flooding occur on lower superficial velocity. Figure 1.2 depicts the phenomenon. 


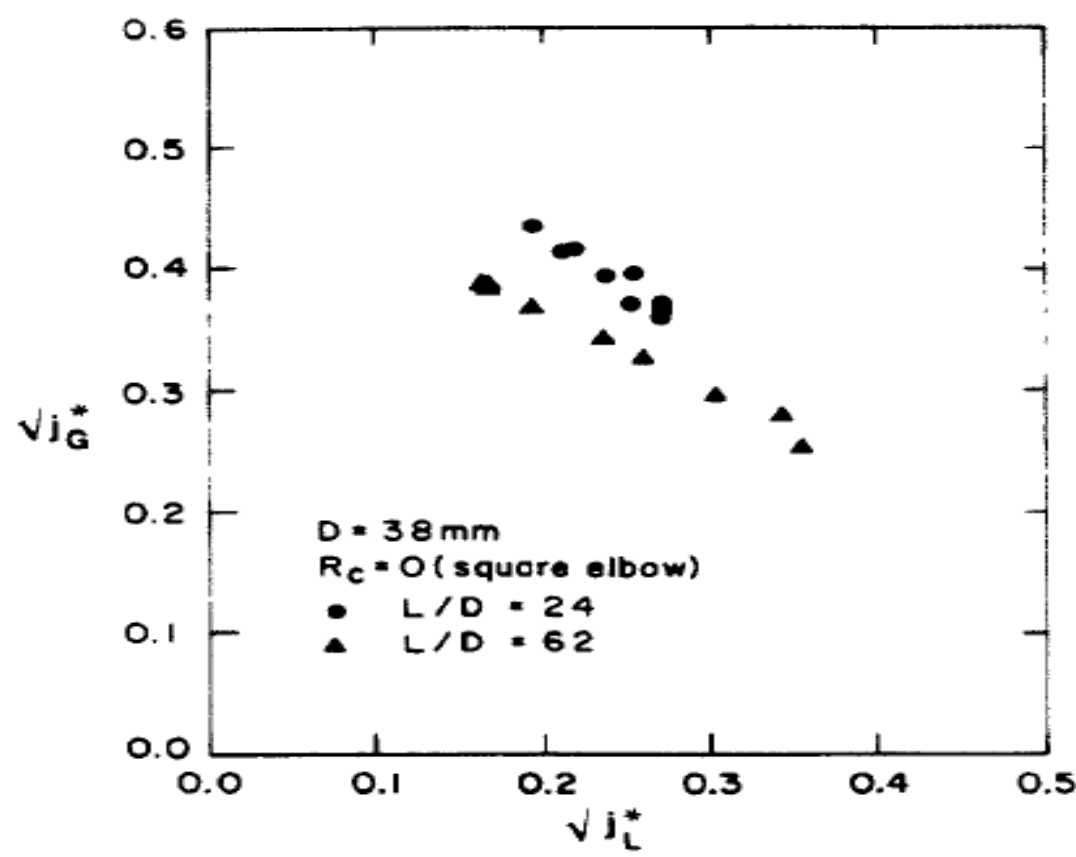

Figure 1.2 Curve of influence of $L / D$ to flooding. For $L / D=24$ and $L / D=62$ Siddiqui et.al. [5]

Wongwises [6] conducted research on influence of $L / D$ to flooding phenomenon in horizontal pipe of $64 \mathrm{~mm}$ in diameter connected to elbow with varied inclinations. L/D for the research were $L / D=13, L / D=22, L / D=44$. The result was bigger $L / D$ for fixed diameter, then flooding was occured in lower superficial velocity of air (JG) as depicted in Figure 1.3.

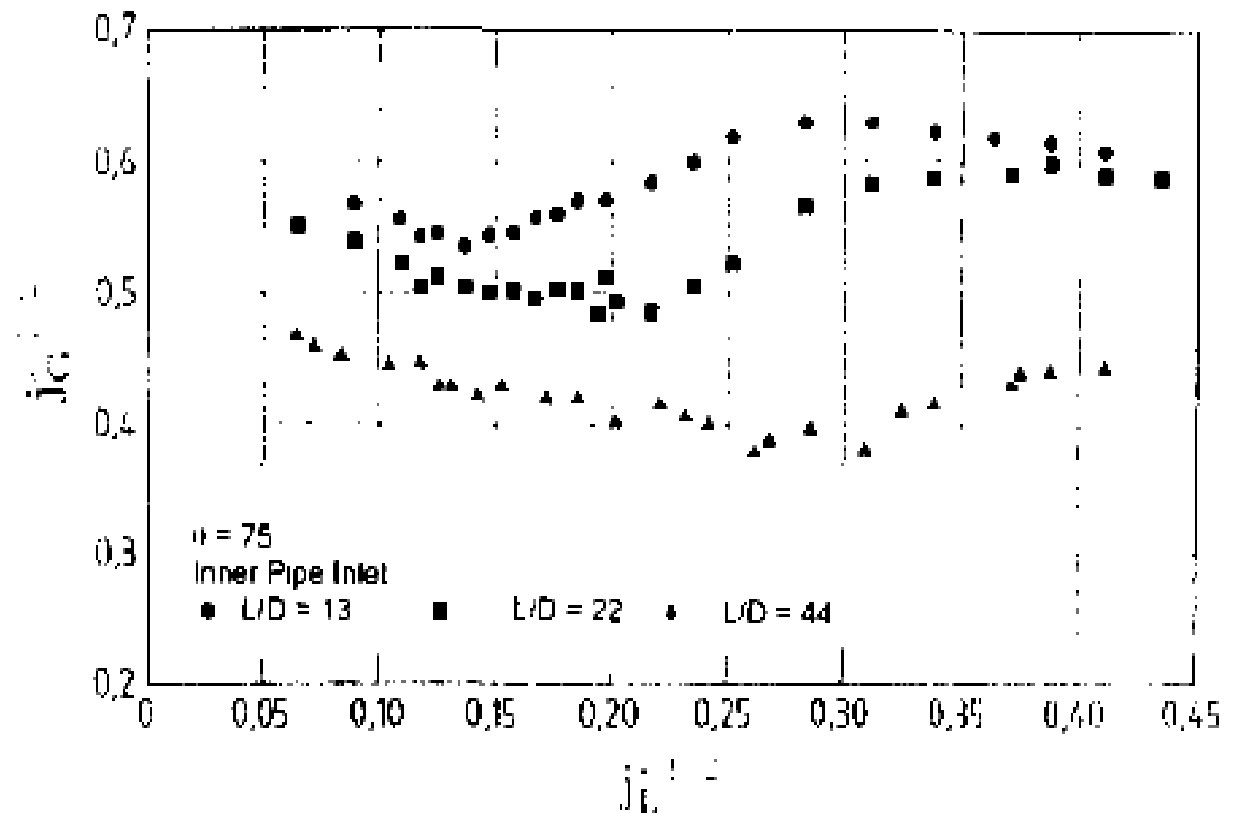

Figure 1.3 Curve of influence of $L / D$ to flooding. For $L / D=13, L / D=22, L / D=44$. Wongwises [6] 
This research was different from previous researches in investigate the influence of length of horizontzal pipe to floding. The employed pipe was acrylic one of $25.4 \mathrm{~mm}$ in diameter connected to elbow with inclination of $50^{\circ}$. Ratio of length of pipe to diameter were $L / D=25, L / D=50$ and $L / D=94.5$. The results of the research were presented in onset of flooding figures to $\mathrm{JL}=0.016 \mathrm{~m} /, 0.049 \mathrm{~m} / \mathrm{s}, 0.082 \mathrm{~m} / \mathrm{s}$ for $\mathrm{L} / \mathrm{D}$ as presented previously.

\section{Methodology}

The main equipment for this research were: upper tank, testing section (elbow with angle of $50^{\circ}$ ), and horizontal pipe manufactured from acrylic (diameter of $25.4 \mathrm{~mm}$ ) to make easy for observation of flow phenomenon, lower tank, air compresor to supply pressurized air of 4-5 bar, a centrifugal pump, three instruments to measure water flow of rotameter type, an air flowmeer, and a high speed camera. The main equipment for this researh was depicted in Figure 2.1.

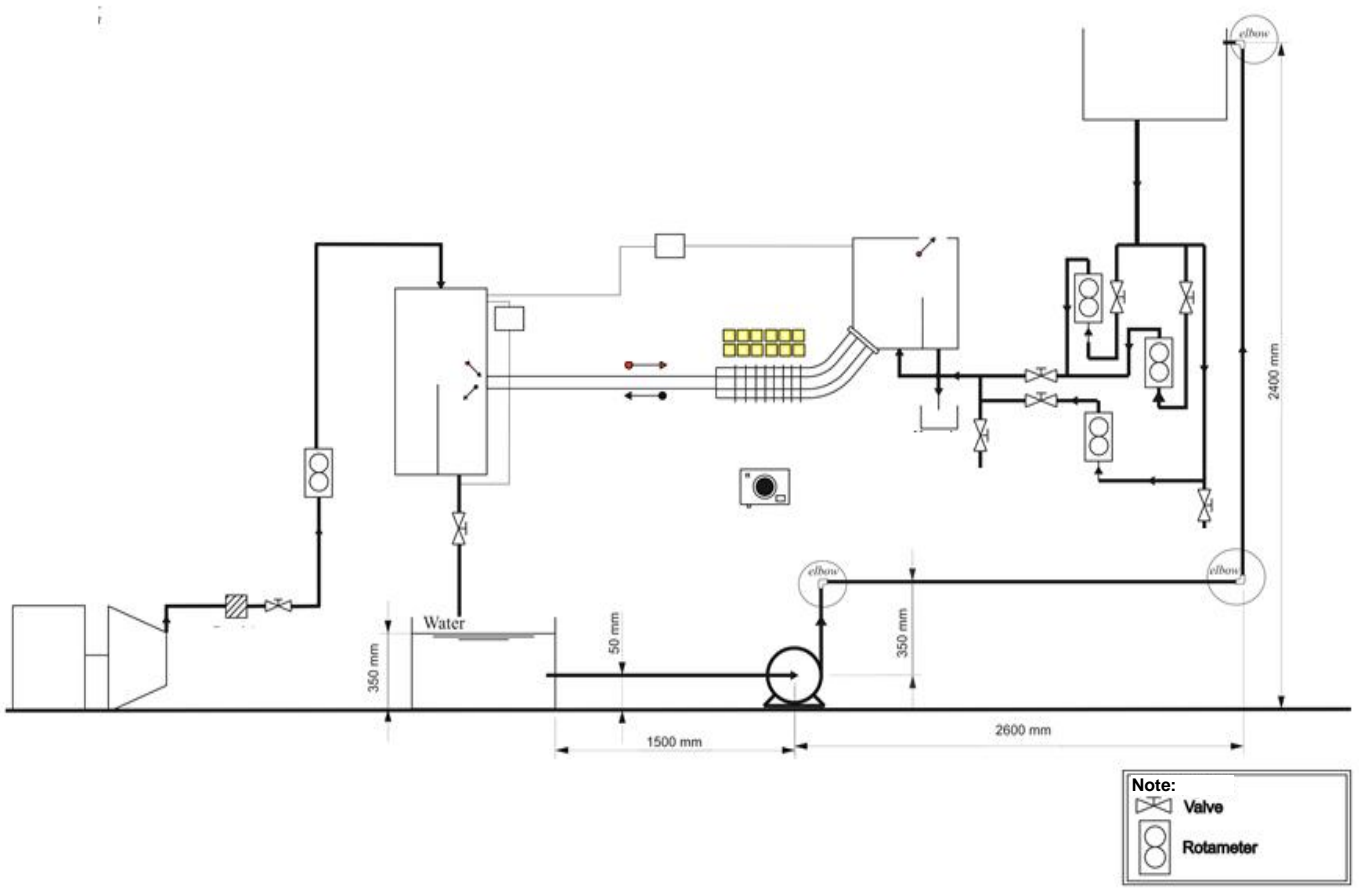

Figure 2.1 Schematic diagram of research apparatus

At first, water was flown from upper tank to testing section and come out from horizontal pipe to lower tank. At the same time, air from compressor flow into air flowmeter and then flow into lower tank, testing section, and come out thru upper tank so that stratified countercurrent water-air flow generated. Then water flow was controlled to certain magnitude and air flow was increased $5 \mathrm{lpm}$ in gradual $(\mathrm{JG}=0.1646 \mathrm{~m} / \mathrm{s})$, from 0 Ipm until flooding was occured.

To convert from flow rate $(Q)$ to superficial velocity $(J)$, the following equations were employed:

$$
\begin{aligned}
& J_{L}=\frac{4 Q_{L}}{\pi D^{2}} \\
& J_{G}=\frac{4 Q_{G}}{\pi D^{2}}
\end{aligned}
$$




$$
\begin{gathered}
I_{L}^{*}=J_{L} \cdot \sqrt{\frac{\rho_{L}}{g \cdot D\left(P_{L}-\rho_{G}\right)}} \\
I_{G}^{*}=I_{G} \cdot \sqrt{\frac{P_{G}}{g \cdot D\left(P_{L}-\rho_{G}\right)}}
\end{gathered}
$$

In this research, time interval to change JG was 15 seconds. Air flow was gradually changed until onset of flooding (CCFL) phenomenon was occured. During investigation, matrix which contain on going flow pattern and time of the occurence of the flow pattern was constructed. From the beginning when water was flown into upper tank until onset of flooding phenomenon occured, the flow phenomenon in testing section was recorded using high speed camera Nikon J4. Visual data, i.e. in form of video, then converted into picture in jpg format by using Free Video v. 50 software. The number of pictures from the conversion was 60 (sixty) pictures per seconds, which followed the camera frame rate (60 fps).

After the image was acquired, then flow pattern was detected by using matrix which constructed previously. The results of detection then consructed into flooding curve for $L / D=25, L / D=50$, and $L / D=94.5$. In this research, besides made the flooding curve also the image when onset of flooding was occured also presented for $\mathrm{JL}=0.016 \mathrm{~m} / \mathrm{s}$, $0.049 \mathrm{~m} / \mathrm{s}$. and $0.082 \mathrm{~m} / \mathrm{s}$ for each L/D.

\section{Results AND Discussion}

In this research, the main objective was to explain the influence of length of horizontal pipe to flooding. This explananation took the form of flooding curve for $L / D=25$, $\mathrm{L} / \mathrm{D}=50$, and $\mathrm{L} / \mathrm{D}=94.5$, and also presented the image when flooding occur for superficial velocity of water (JL) of $0.016 \mathrm{~m} / \mathrm{s}, 0.049 \mathrm{~m} / \mathrm{s}, 0.082 \mathrm{~m} / \mathrm{s}$, for L/D =25, L/D = 50 and $\mathrm{L} / \mathrm{D}=94.5$.

\subsection{Flooding curve}

Flooding curve is a curve which drew in coordinate $\mathrm{JG}_{\mathrm{G}}{ }^{*}-\mathrm{JL}_{\mathrm{L}}{ }^{*}$ and $\mathrm{JG}_{\mathrm{G}}{ }^{*}$ and represent dimensionless superficial velocity of air as vertical axis and $J_{L}{ }^{*}$ which represent dimensionless superficial velocity of water as horizontal axis. Each point in coordinate of flooding curve represent value of certain $\mathrm{JG}_{\mathrm{G}}{ }^{*}-\mathrm{J}_{\mathrm{L}}{ }^{*}$ when flooding occurs.

From the investigation, flooding curve for $L / D=25, L / D=50$, and $L / D=94.5$ could be presented as in Figure 3.1.

Figure 3.1 showed the comparison of flooding curve of this research and Siddiqui et.al [5]. It was known that the trend of flooding curve was similar, in which flooding occured in the lower value of $\sqrt{\mathrm{J}_{G}^{*}}$ for higher value of L/D. In Figure 3.1, it was obvious that for same value of $\sqrt{\mathrm{J}_{\mathrm{L}}^{*}}$, the flooding from Siddiqui et.al [5] for $L / D=24$ was occurred at lower value of $\sqrt{J_{G}^{*}}$ compared to flooding in this studi for $L / D=25$. This was caused by difference in pipe diameter and inclination angle between riser and horizontal pipe. In Siddiqui et.al., the pipe was38 $\mathrm{mm}$ in diameter while for this researh was $25.4 \mathrm{~mm}$ with angle between riser and horizontal pipe was $50^{\circ}$. 


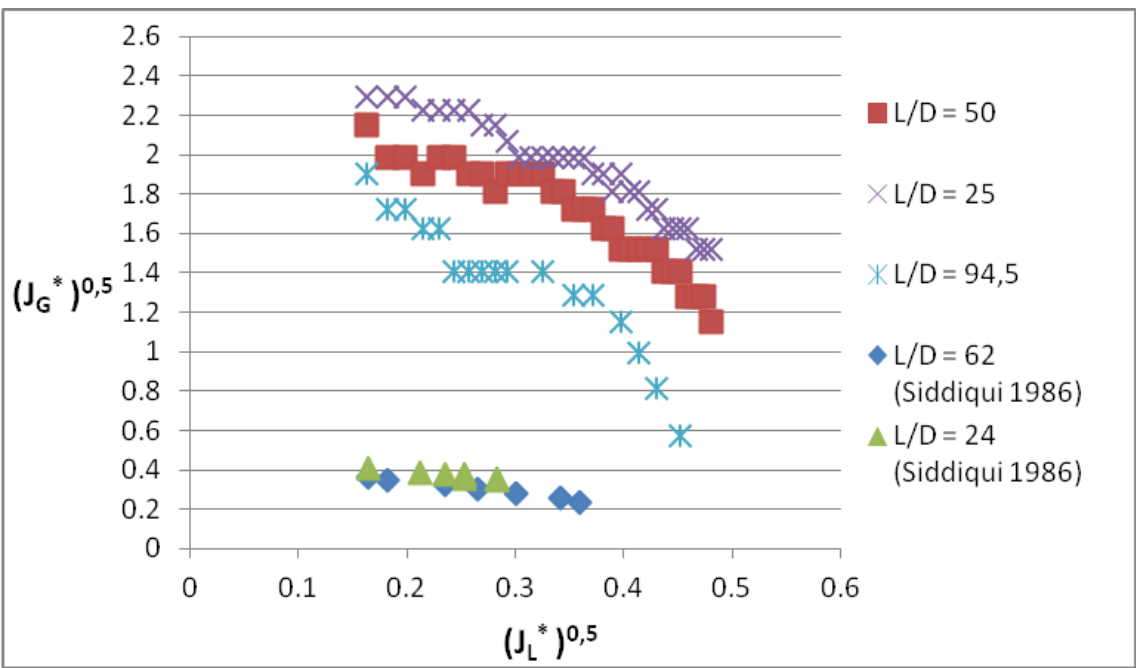

Figure 3.1 Comparison of flooding curve to variation of $L / D$.

(This research, $L / D=25, L / D=50$ and $L / D=94,5$; Siddiqui et.al. [5], $L / D=24$ and $L / D=62$.)

Explanation of floding phenomenon was easier when L/D become higher because for longer horizontal pipe, higher water accumulation in testing section near elbow. Water accumulation was caused by, in longer pipe, water which flow into testing section was not immediateately flow into lower tank so that accumulation occured near elbow. With the occurence of water accumulation then increase in height of hydraulic spike in testing section so that void fraction become smaller. This condition makes air velocity flow above water phase become faster which followed by higher friction force on the interface of watre-air. This higher friction force generate unstable wave on interface and grow into slug and flooding. This result was in agreement Vijayan et.al [7] research and Navarro [8].

\subsection{Position of onset-flooding}

Onset of flooding is a phenomenon of the occurence of unstable wave with high amplitude (occurence of chaotic flow pattern) and was followed by droplet enrrainment from the peaks of unstable waves, Bankoff and Lee [9]. In this research, the captured images wer showing of the position of onset of flooding for different value of $L / D$. In the Figure 3.2, it was presented that for higher L/D (horizontal pipe getting longer) and $\mathrm{JL}=$ $0.016 \mathrm{~m} / \mathrm{s}$ the position of onset flooding was shifted toward leg of elbow.

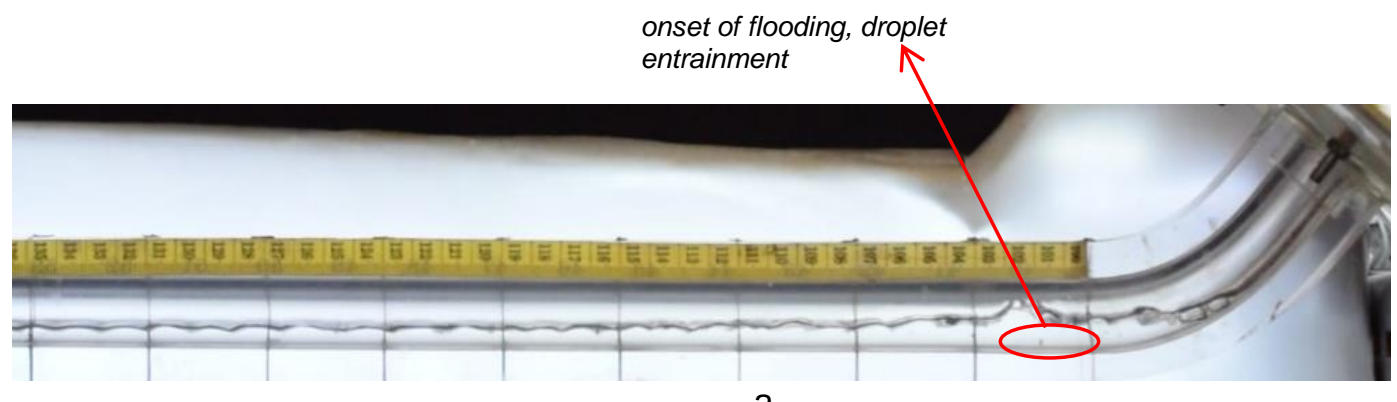

a

Figure 3.2 Visualization of flow pattern to $J_{L}=0.016 \mathrm{~m} / \mathrm{s}$. (a) onset of flooding position for $L / D=25$, $J_{G}=2.47 \mathrm{~m} / \mathrm{s}$ 


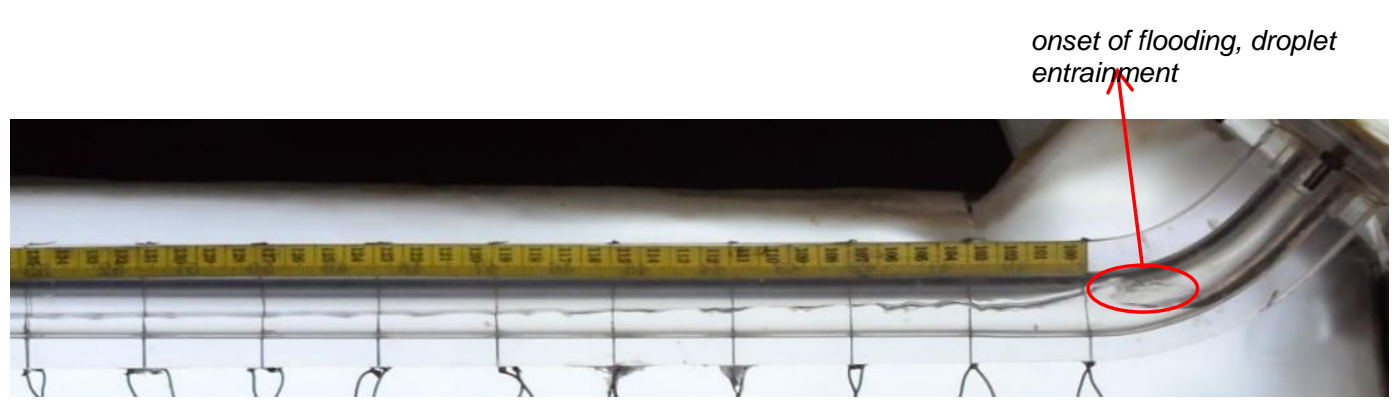

(b)

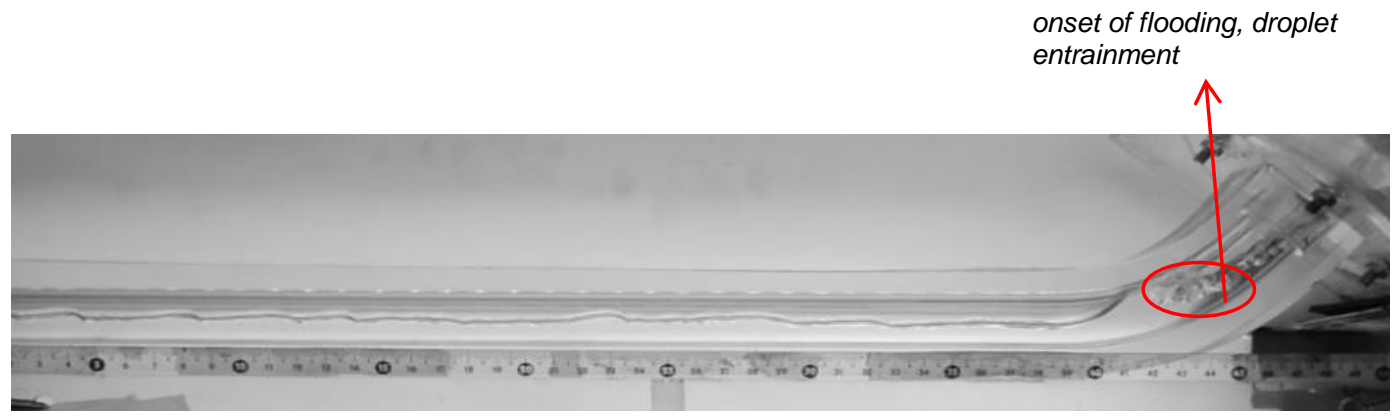

(c)

Figure 3.3 Visualization of flow pattern to $J_{L}=0.016 \mathrm{~m} / \mathrm{s}$. (b) onset of flooding position for $L / D=50$, $J_{G}=1.97 \mathrm{~m} / \mathrm{s} ;$ (c) onset of flooding position for $L / D=94.5$ and $J_{G}=1.32 \mathrm{~m} / \mathrm{s}$

In Figure 3.4, onset of flooding position for $\mathrm{J}_{\mathrm{L}}=0,049 \mathrm{~m} / \mathrm{s}$ was depicted. It was clear that when L/D higher, onset of flooding position was closing to bottom leg of elbow. It was observed that onset of flooding position shifted to away from elbow comparing with onset of flooding position on $\mathrm{J} L=0,016 \mathrm{~m} / \mathrm{s}$.

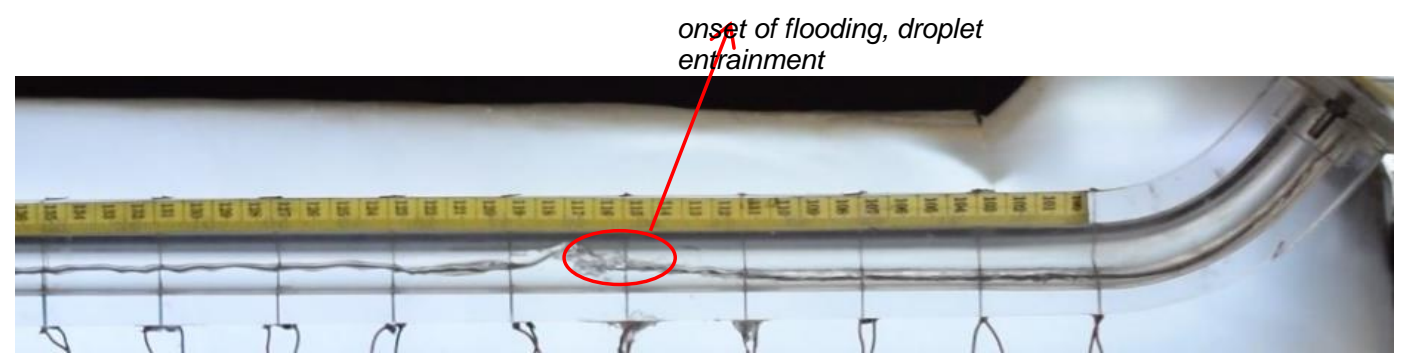

(a)

Figure 3.4 Visualisation of flow pattern for $J_{L}=0.049 \mathrm{~m} / \mathrm{s}$. (a) onset of flooding position for $L / D=50$, $J_{G}=1.97 \mathrm{~m} / \mathrm{s}$ 


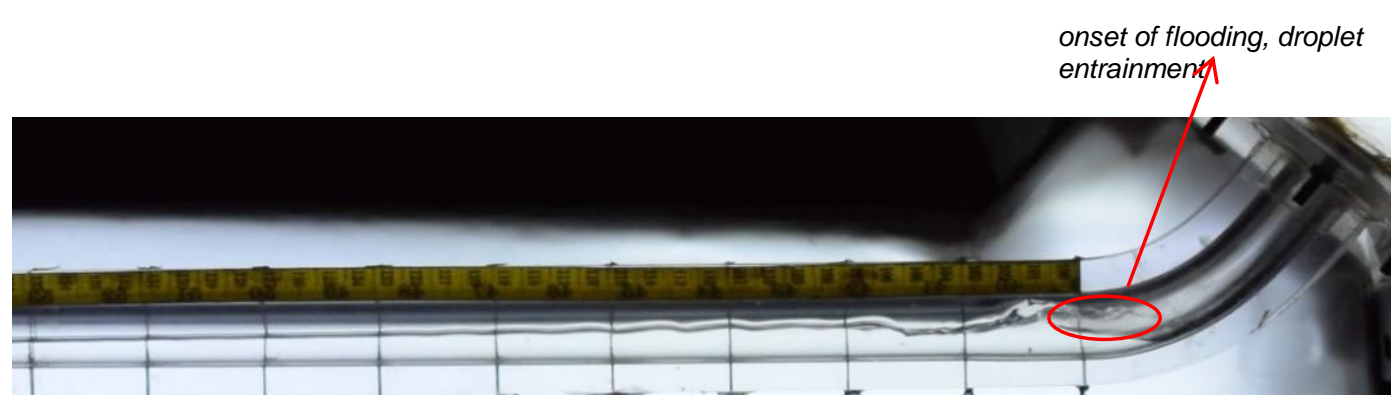

(b)

Figure 3.4 Visualisation of flow pattern for $J_{L}=0.049 \mathrm{~m} / \mathrm{s}$. (b) onset of flooding position for $L / D=50$, $J_{G}=1.64 \mathrm{~m} / \mathrm{s}$

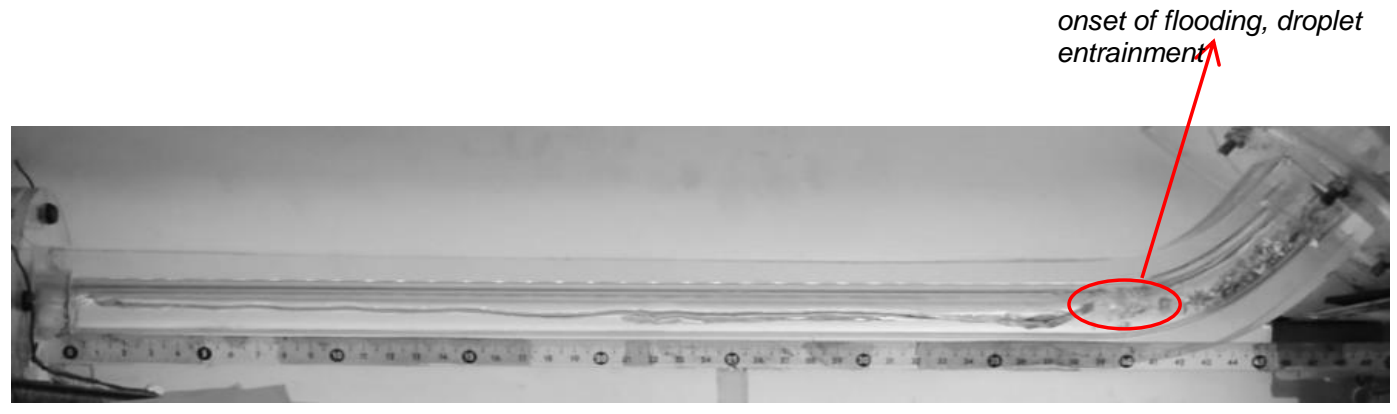

(c)

Figure 3.5 Visualisation of flow pattern for $J_{L}=0,049 \mathrm{~m} / \mathrm{s}$. (c) onset of flooding position for $L / D=$ 94.5 and $J_{G}=0.99 \mathrm{~m} / \mathrm{s}$

It was observed that for $J_{L}=0,082 \mathrm{~m} / \mathrm{s}$, bigger the value of $L / D$ then onset of flooding position give same trend in which closer to bottom leg of elbow. Onset of flooding position on $J_{L}=0,082 \mathrm{~m} / \mathrm{s}$ was shifted to away from elbow compared with onset of flooding position on previous $J_{L}\left(J_{L}=0,016 \mathrm{~m} / \mathrm{s}\right.$ and $\left.J_{L}=0,049 \mathrm{~m} / \mathrm{s}\right)$. It was observed in Figure 3.5.

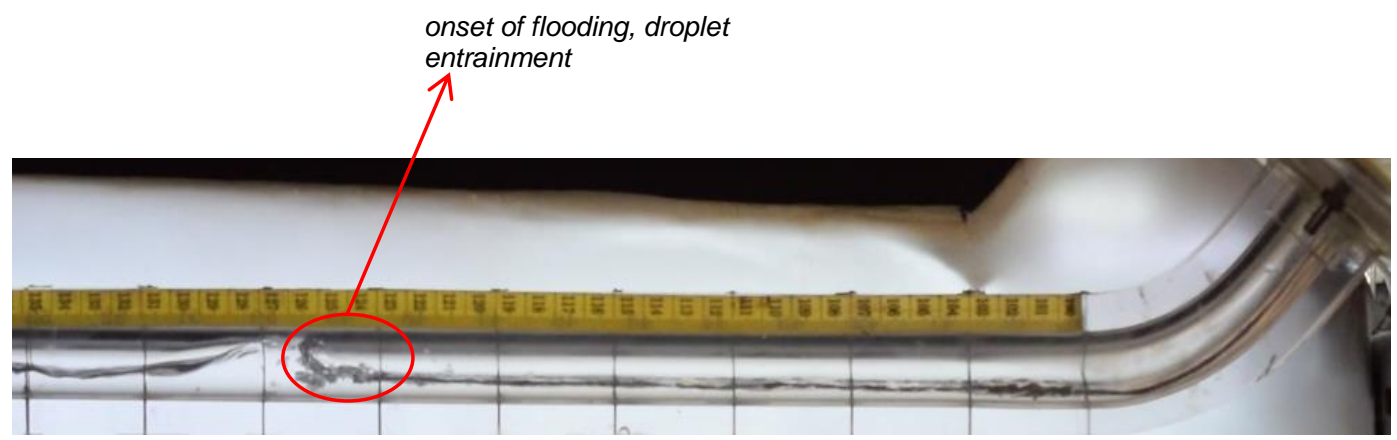

(a)

Figure 3.6 Visualisation of flow pattern for $J_{L}=0,082 \mathrm{~m} / \mathrm{s}$. (a) onset of flooding position for $L / D=94.5 ; J_{G}=1.48 \mathrm{~m} / \mathrm{s}$ 


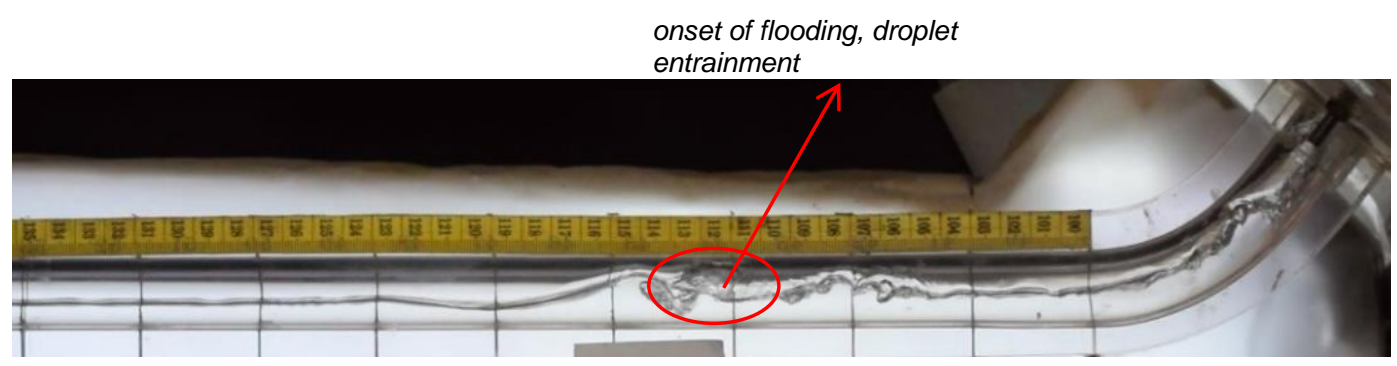

(b)

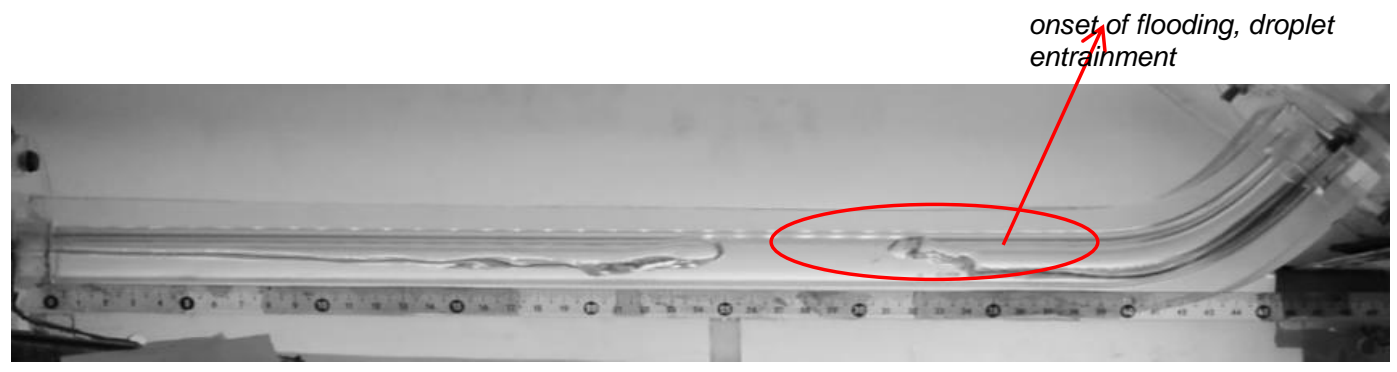

(c)

Figure 3.6 Visualisation of flow pattern for $J_{L}=0,082 \mathrm{~m} / \mathrm{s}$. (b) onset of flooding position for $L / D=50$, $J_{G}=1.15 \mathrm{~m} / \mathrm{s}$; (c) onset of flooding position for $L / D=94.5$ and $J_{G}=0.49 \mathrm{~m} / \mathrm{s}$

Shifting of onset of flooding position was away from elbow for increasing $J_{L}$ value on same L/D. Increase of $J_{L}$ made hydraulic jump become higher and away from elbow. When air speed was increasing then on peak of hydraulic jump occurs unstable wave. When the air speed increased further, then amplitude of unstable wave becomes bigger because friction on interphase. This lead to slug generation and onset of flooding occurs on position away from elbow. he result was in accordance Wongwises [10] and Apip et.al. [11].

\section{CONCLUSION}

According to the results of research on influence of length of horizontal pipe to flooding of concurrent flow of water-air, it can be concluded that bigger of the value of L/D (longer horizontal pipe) made flooding occurs faster or lower of superficial velocity of air. For the bigger value of $L / D$ the position of onset of flooding closer to elbow. But, for fixed value of $L / D$ then position of onset of flooding was shifted away from elbow when velocity of artificial water becomes higher.

In future, it needs to investigate the influence of the varied length of horizontal pipe to enrich the data base on design of horizontal pipe of reactor hot leg. Also the investigation on the influence of geometric shape of inlet and outlet of water and also influence of varied of pipe diameters need to be conducted in future.

\section{REFERENCES}

[1] Y. Taitel and A.E. Dukler, Flow Pattern Transitions in Gas - Liquid Systems : Measurement and Modeling, Multiphase Science and Technology, vol 2, Springer, 1986.

[2] Seong-Kwon Kang, In- Cheol Chu, Hee Cheon NO, and Moon-Hyun Chun, "Air - Water Countercurrent Flow Limitation In a Horizontal Pipe Connected To An 
Inclined Riser", Journal Of The Jorean Nuclear Society, vol. 31, no. 6, pp. 548 560, 1999.

[3] Deendarlianto, Christophe Vallee, Dirk Lucas, Mathias Beyyer, Heiko., Carl, Helmar Pietruske, "Experimental Study on The Air/Water Counter Current Flow Limitation In a Model Of The Hot Leg Of a Pressurized Water Reactor", Nuclear Engineering And Design, no. 238, pp. 3389 - 3402, 2008.

[4] Apip Badarudin, Indarto, Deendarlianto, Hermawan, Aji Saka, M. Fikri Haykal Syarif, Aditya Wicaksono, "Observasi Pola Aliran Dua Fase Air - Udara Berlawann Arah Pada Pipa Komplek”, IRWNS, 2014.

[5] H. Siddiqui and S. Banerjee, "Flooding In An Elbow Between A Vertical And A Horizontal Or Near Horizontal Pipe”, Int. J. Multiphase Flow, vol. 12, no. 4, pp. 531-541, 1986.

[6] S. Wongwises, "Flooding In A Horizontal Pipe With Bend", Int. J. Multiphase Flow, vol. 22, no. 1, pp. 195-201, 1996.

[7] M. Vijayan, S. Jayanti, and A.R. Balakrishnan, "Effect Of Tube Diameter On Flooding", International Journal Of Multiphase Flow, vol. 27, pp. 797-816, 2001.

[8] Moyses Alberto Navarro, "Study Of Countercurrent Flow Limitation In A Horizontal Pipe Connected To An Inclined One", Nuclear Engineering And Design, vol. 235, pp. 1139-1148, 2005.

[9] S. George Bankoff and Sang Chun Lee, A Critical Review Of The Flooding Literature, Multiphase Science And Technology, vol 2, Springer, 1986.

[10] S. Wongwises, "Experimental Investigation Of The Two-Phase Countercurrent Flow Limitation In A Bend Between Horizontal And Inclined Pipe", Experimental Thermal And Fluid Science, vol. 8, pp. 245-259, 1994.

[11] Apip Badarudin, Indarto, Deendarlianto, Suprianta Setiawan Putra, Sinung Tirtha, Venti Yoanita, Marcellinus Sindhu, "Visualisasi Mekanisme Flooding Aliran Counter-Current Air-Udara Pada Simulator Hotleg Dengan L/D = 50”, RETII, 2016. 